\title{
Depression and Anxiety
}

RESEARCH ARTICLE

\section{Late - Life Depression in North Greece: Prevalence and Un- der-Detection}

\section{Konstantinos Argyropoulos, Aikaterini Saropoulou and Eleni Jelastopulu*}

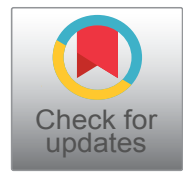

\author{
Department of Public Health, School of Medicine, University of Patras, Greece
}

*Corresponding author: Eleni Jelastopulu, Department of Public Health, School of Medicine, University of Patras, 26500 Rio Patras, Greece, Tel: +30-2610-969878

\begin{abstract}
Depression is the most frequent cause of emotional suffering on late life. The purpose of the present study was to estimate the prevalence of depression and to assess possible under-diagnosis of depressive symptoms in the elderly. A cross-sectional study was conducted among the members of the open day care centers for older people in the municipality of Pella, North Greece. A questionnaire was developed to collect basic demographic data, including three questions from the "European Health Interview Survey", regarding self-reported and/or by a physician diagnosed depression. Moreover, to all participants the Greek validated version of the Geriatric Depression Scale (GDS-15) was applied, to screen for depressive symptoms. A total of 241 individuals took part in the study. According to the GDS, $34.9 \%$ of the participants revealed having depressive symptoms, $27.5 \%$ moderate and $7.5 \%$ severe. Having ever been affected with chronic depression reported $30.4 \%$, of them $68.4 \%$ had been diagnosed by a medical doctor and $20.8 \%$ had received medication. Of the 160 subjects who reported never been affected by a depression, $26.9 \%$ and $3.8 \%$ screened positive for moderate and severe depressive symptoms, respectively. In seven individuals who reported not to know if they have/had depression, depressive symptoms were observed in $85.7 \%$ applying the GDS-15. Depression in the elderly in North-Greece show a high prevalence and appears to be an under-diagnosed disease. The application of GDS-15 by general practitioners would increase their ability to detect and treat depression.
\end{abstract}

\section{Introduction}

Late-life Depression (LLD) is neither a natural part of ageing nor a sign of weakness, but it affects up to $13.3 \%$ of older people worldwide [1]. Life's changes such as retirement, the death of loved ones or declining health can sometimes trigger depression [2]. The consequences of untreated LLD include serious functional impair- ment with poor quality of life, increased use of alcohol and high rates of suicide attempts [3].

While depression and sadness might seem to go hand in hand, many depressed seniors claim not to feel sad at all and present atypical symptoms. In fact, memory deficits and unexplained physical complaints, such as fatigue, diffuse pain, back and chest syndromes or worsening headaches, are often the predominant symptoms of $\operatorname{LLD}[2,4]$.

Many depressed older adults may not recognize the symptoms of depression, or don't take the steps to get the help they need, because depression is masked by somatic symptoms and elderly are reluctant to talk about their feelings. In addition, due to the atypical presentation of LLD, general practitioners in primary health care seem to fail in terms of diagnosing depressive symptoms in older people $[5,6]$.

\section{Purpose}

The purpose of the present study was to estimate the prevalence of depression in older adults in North Greece, to examine associations with major risk factors such as gender, educational level, marital status, comorbidity and to determine possible under-detection of depressive symptoms.

\section{Method}

We conducted a cross-sectional study of the registered and active members of the 13 open day-care centers for older people in the municipality of Pella, North Greece (two open day-care centers in Giannitsa and the rest in Kria Vrysi, New and Old Pella, Athira, Rachona, Axos, Old Mylopota, Karyotissa, Esovalta, Acrolimni and Agios Lou- 
kas), from March to June 2016. All open day-care centers for older people in the Municipality of Pella were selected and in each of them the questionnaires distributed either in the morning or in the afternoon. A representative sample of the elderly in each open day-care center was fairly collected. Based on the total number of members of all open day-care centers for older people in Pella, the minimum sample size was calculated at 180 subjects. The study period was 4 months therefore it was possible to collect more than calculated. All participants were 60 -yearsold and above. This is the minimum age someone must have, to enroll in an open day-care center for older people in Greece. Community based open day-care centers are public in Greece and offer a professionally managed environment for older adults. Typically, this type of facilities provides a safe and secure setting for elders during the daytime hours that includes social engagement, public awareness and other services such as art therapy, occupational therapy and preventive medicine services.

An anonymous questionnaire was developed to collect basic demographic and socioeconomic data; the questionnaire included three questions from the European Health Interview Survey regarding self- reported and/or physician-diagnosed depression both in the last 12 months and during their lifetime [7]. Moreover, all participants were given the validated Greek version of the 15-item Geriatric Depression Scale (GDS-15) to screen for depressive symptoms and to estimate the prevalence of depression in this particular population group. Patients with scores of 0-5 are considered normal; a score of 6-10 indicates moderate depression, and 11-15 indicates severe depression $[8,9]$.

The results of the GDS-15 were compared to the corresponding answers of the European Health Interview Survey questions to estimate possible under-diagnosis in depression. Furthermore, various associations between the GDS-15 score and recorded basic parameters were examined. During the study period, the same researcher visited one of the day-care centers daily, in either the morning or the afternoon, and distributed the questionnaires to the members. In the most cases, a face-to-face interview was performed, as requested by the great majority of respondents. Participants with any type of dementia were excluded from the studied population.

Statistical analysis was performed with SPSS for Windows v.19.0 Statistical Package. A chi square test was used to test the difference between categorical variables. $P<0.05$ was considered as statistically significant.

Ethical approval for the conduction of the study was obtained from the Advisory Board of the open day-care centers for older people in the Municipality of Pella and every effort has been made to adhere to recommended best practice to protect the interests and welfare of the participants. Verbal informed consent explaining the objectives and procedures was obtained from all participants before the study and they were ensured of anonymity and confidentiality.
Table 1: Sociodemographic characteristics of the study population $(\mathrm{N}=241)$.

\begin{tabular}{|c|c|c|}
\hline Characteristics & $\mathbf{N}$ & $\%$ \\
\hline \multicolumn{3}{|l|}{ Gender } \\
\hline Male & 121 & 50.4 \\
\hline Female & 119 & 49.6 \\
\hline \multicolumn{3}{|l|}{ Nationality } \\
\hline Greek & 238 & 98.8 \\
\hline Other & 3 & 1.2 \\
\hline \multicolumn{3}{|l|}{ Mean age in years \pm SD } \\
\hline \multicolumn{3}{|l|}{ Place of residence } \\
\hline Urban (City of Giannitsa) & 165 & 68.5 \\
\hline Rural & 76 & 31.5 \\
\hline \multicolumn{3}{|l|}{ Member of open-day-care-center } \\
\hline Giannitsa & 151 & 62.4 \\
\hline Old Pella & 17 & 7.1 \\
\hline Karyotissa & 17 & 7.1 \\
\hline Rachona & 15 & 6.2 \\
\hline Krya Vrisi & 14 & 5.8 \\
\hline Other rural centers & 27 & 11.4 \\
\hline \multicolumn{3}{|l|}{ Marital status } \\
\hline Married & 137 & 56.8 \\
\hline Not married & 10 & 4.1 \\
\hline Widowed & 85 & 35.3 \\
\hline Divorced & 9 & 3.7 \\
\hline \multicolumn{3}{|l|}{ Having children } \\
\hline Yes & 219 & 90.9 \\
\hline No & 22 & 9.1 \\
\hline \multicolumn{3}{|l|}{ Living alone at home } \\
\hline Yes & 171 & 71.0 \\
\hline No & 70 & 29.0 \\
\hline \multicolumn{3}{|l|}{ Education level } \\
\hline Primary Education and illiterate & 190 & 79.2 \\
\hline Secondary Education & 45 & 18.8 \\
\hline Higher education & 5 & 2.1 \\
\hline \multicolumn{3}{|c|}{ Economic status (Monthly income in Euro) } \\
\hline$<500$ & 97 & 40.2 \\
\hline $500-1000$ & 117 & 48.5 \\
\hline $1000-2000$ & 27 & 11.2 \\
\hline$>2000$ & 0 & 0.0 \\
\hline \multicolumn{3}{|l|}{ Comorbidities } \\
\hline Myocardial infarct & 11 & 4.6 \\
\hline Stroke & 13 & 5.4 \\
\hline Hypertension & 80 & 33.2 \\
\hline Diabetes & 37 & 15.4 \\
\hline Cancer & 25 & 10.4 \\
\hline Parkinson's disease & 7 & 2.9 \\
\hline Other & 57 & 23.6 \\
\hline \multicolumn{3}{|c|}{$\begin{array}{l}\text { Visiting frequency of the of open-day-care- } \\
\text { center }\end{array}$} \\
\hline$<1$ monthly & 25 & 10.4 \\
\hline < 1 weekly & 120 & 49.8 \\
\hline Almost daily & 96 & 39.8 \\
\hline
\end{tabular}

\section{Results}

A total of 241 individuals took part in the study, $62.4 \%$ visiting the open day-care centers of Giannitsa; $50.4 \%$ were men, mean age of all respondents was 75 years. Table 1 present the basic demographic data of the studied population. 
Table 2: Depression in association to various demographic and socioeconomic characteristics.

\begin{tabular}{|c|c|c|c|c|}
\hline \multirow[t]{2}{*}{ Characteristics } & \multicolumn{4}{|c|}{ Depression according to GDS-15 (in \%) } \\
\hline & None & Moderate & Severe & Total n (\%) \\
\hline Total participants & 65.0 & 27.5 & 7.5 & $241(100)$ \\
\hline \multicolumn{5}{|l|}{ Gender $^{*}$} \\
\hline Male & 68.6 & 27.3 & 4.1 & $121(50.2)$ \\
\hline Female & 60.5 & 28.6 & 10.9 & $119(49.8)$ \\
\hline \multicolumn{5}{|l|}{ Marital Status* } \\
\hline Married & 74.5 & 21.2 & 4.4 & $137(56.8)$ \\
\hline Other & 51.9 & 36.5 & 11.5 & $104(43.2)$ \\
\hline \multicolumn{5}{|l|}{ Educational Level $^{*}$} \\
\hline$<6$ years & 60.5 & 30.5 & 8.9 & $190(78.8)$ \\
\hline Over 6 years & 80.0 & 18.0 & 2.0 & $51(21.2)$ \\
\hline \multicolumn{5}{|l|}{ Family Income (€) } \\
\hline$<500$ & 60.8 & 30.9 & 8.2 & $97(40.2)$ \\
\hline $500 \leq 1000$ & 67.5 & 24.8 & 7.7 & $117(48.6)$ \\
\hline$>1000$ & 66.7 & 29.6 & 3.7 & $27(11.2)$ \\
\hline \multicolumn{5}{|l|}{ Co-morbidity } \\
\hline \multicolumn{5}{|c|}{ Myocardial infarction ${ }^{* *}$} \\
\hline Yes & 27.3 & 72.7 & 0.0 & $11(4.6)$ \\
\hline No & 66.5 & 25.7 & 7.8 & $230(95.4)$ \\
\hline \multicolumn{5}{|l|}{ Hypertension $^{\star *}$} \\
\hline Yes & 53.8 & 35.0 & 11.3 & $80(33.2)$ \\
\hline No & 70.2 & 24.2 & 5.6 & $161(66.8)$ \\
\hline \multicolumn{5}{|l|}{ Diabetes* $^{*}$} \\
\hline Yes & 45.9 & 37.8 & 16.2 & $37(15.4)$ \\
\hline No & 68.1 & 26.0 & 5.9 & $204(84.6)$ \\
\hline \multicolumn{5}{|l|}{ Living Conditions } \\
\hline Alone & 66.7 & 26.9 & 6.4 & $171(71.0)$ \\
\hline Not alone & 60.0 & 30.0 & 10.0 & $70(29.0)$ \\
\hline
\end{tabular}

" $p<0.05,{ }^{* *} p<0.01$.

Table 3: Comparison of results between Geriatric Depression Scale (GDS-15) and European Health Interview Survey (EHIS) questions.

\begin{tabular}{|c|c|c|c|c|}
\hline \multirow{2}{*}{$\begin{array}{l}\text { Self-reported Depression according to EHIS } \\
\text { Questionnaire }\end{array}$} & \multicolumn{4}{|c|}{ Depression (GDS-15) } \\
\hline & None $\%$ & Moderate \% & Severe \% & Total n (\%) \\
\hline \multicolumn{5}{|l|}{ HS. $4^{*}(n=240)$} \\
\hline Yes & 60.3 & 28.8 & 11.0 & $73(30.4)$ \\
\hline No & 69.4 & 26.9 & 3.8 & $160(66.7)$ \\
\hline Don't Know & 14.3 & 28.6 & 57.1 & $7(2.9)$ \\
\hline \multicolumn{5}{|l|}{ HS. ${ }^{* *}(n=240)$} \\
\hline Yes & 50.0 & 34.6 & 15.4 & $26(10.8)$ \\
\hline No & 68.4 & 25.7 & 5.8 & $206(85.8)$ \\
\hline Don't Know & 25.0 & 50.0 & 25.0 & $8(3.3)$ \\
\hline
\end{tabular}

"Do you have or have ever had depression in your life?

*Have you experienced depression over the last 12 months?

According to the results of the GDS-15, 35\% (84) of the respondents had depressive symptoms, particularly 27.5\% had moderate and $7.5 \%$ severe depression ( $\mathrm{Ta}$ ble 2). Having self-reported chronic depression declared $30.4 \%$, of those $68.4 \%$ were diagnosed by a physician and $20.8 \%$ received antidepressants. Of the 160 subjects who reported that they had never been affected by depression, $26.9 \%$ and $3.8 \%$ screened positive for moderate and severe depressive symptoms, respectiveIy (Table 3). In the 7 individuals who reported they did not know if they had depression, depressive symptoms were observed in $85.7 \%$ (6) based on the results of the GDS-15. Depressive symptoms were more frequent in women than in men (mean score 5.35 vs. $4.35, P<0.05$ ) and in not married (single, widowed) compared to married participants (mean score 5.92 vs. 4.01, $P<0.05$ ). Furthermore, depression was more frequent in older adults with a chronic disease such as a severe heart disorder $(P=0.003)$, hypertension $(P<0.001)$, diabetes $(P=$ $0.015)$ and Parkinson's disease $(P=0.008)$ than in those without a comorbidity and in participants with a lower educational level (mean score 5.2 vs. 3.4, $P=0.028$ ) (See Table 2).

\section{Discussion}

Our study revealed that a high percentage (approxi- 
mately one in three older adults, 35\%) of the open daycare centers members in Pella suffer from moderate or severe depressive symptoms. Similar findings were observed in previous studies in Greece, whereas in open day care centers in Attica overall LLD prevalence rate was $30.3 \%$ [10] and in a study that was conducted in a rural area in central Greece, the prevalence of depressive symptoms was $39 \%$ [11]. On the other hand, a higher rate was observed according to GDS-15 results in a rural setting in Indian whereas $57.66 \%$ of the elderly were suffering from some type of depression [12] and in a study conducted in Attica and Fokida in Greece, $84.3 \%$ of participants estimated to suffer from both moderate and severe type of depression [13]. The observed variations in the mentioned studies, may be attributed to different characteristics of the rural, urban, and semi urban populations of older people; the cut-off score and the tools that have been used to estimate LLD or to other parameters that were not measured.

In the present study, the prevalence rates of depression are increased in women, in widowed, in those with lower educational level and in older people with chronic diseases. These results provide useful indications that specific variables referring to the elder's sociodemographic profile may affect mental health. The findings support evidence in the literature suggesting that sociodemographic factors may to some extent contribute to the explanation of LLD. In details, the results of the studies performed indicates that female gender, and age are strongly associated with depression in older people $[14,15]$, as well as psychosocial factors such as, isolation, feelings of purposelessness, and recent bereavements mainly the loss of a spouse or partner that reflects loneliness, and lack of social support $[16,17]$. Moreover, lower education level [18] and poor physical health including Illness and disability seem to put elders at risk for depressive symptoms [19].

In addition to the high prevalence of depressive symptoms, our study revealed that a remarkable percentage of the participants was not aware of suffering from depression and had never been diagnosed with this condition. The low self-reported percentage of diagnosed depression far from the screening results with GDS-15, suggesting a substantial under-detection in this specific population group. The results from an analogue study, that we conducted four years ago in West Greece in a similar setting and population are in line with the present research in North Greece [20]. Underdiagnoses of LLD and subsyndromal depression is confirmed from several studies either in general population or nursing homes [21-23]. Several reasons may explain this under diagnosis of depression in late life, a meta-analysis study support that primary care physicians appear to be less successful in identifying depression in older people than in younger adults [5] due to the atypical symptoms of LLD or to the lack of experience and appropriate training [4].

\section{Conclusions}

In conclusion, there is a high prevalence of depression in the elderly. It is associated with specific demographic and socioeconomic characteristics and appears to be an underdiagnosed disease. With regards to the results of the present study, it is recognized that being male elder, more educated, without comorbidities and married relates to a better mental health with less depressive symptoms, giving in this way emphasis to the importance of family, good health and high educational level.

In overall, our findings provide evidence which can be useful to health professionals and managers of health services offered to patients with LLD. Tailored interventions can be developed to support female but also male subjects, those who are older, windowed and less educated in an effort to address issues of compromised mental health. An appropriate screening and treatment of LLD could eventually offer a better quality of life for depressed elders, decreasing health care costs and suicide deaths.

\section{Limitations}

The present study was limited by the fact that it is a cross-sectional study (no inference can be made), the questionnaires were given to subjects only once and the prevalence of depression depends on the cut-off scores used to distinguish between no depression, moderate depression, and severe depression, as well as by the validity of this threshold against the clinical diagnosis. Furthermore, the study was conducted in a specific population, so our findings cannot be generalized for the whole older population.

\section{Acknowledgments}

The authors sincerely thank the Board of the open day-care centers in the municipality of Pella for their permission and facilitation of the present research, as well as all the respondents who kindly agreed to participate in this study.

\section{Funding and Other Support}

This research did not receive any specific grant from funding agencies in the public, commercial, or not-forprofit sectors.

\section{Disclosure of Interest}

The authors declare that they have no competing interest.

\section{References}

1. Beekman AT, Copeland JR, Prince MJ (1999) Review of community prevalence of depression in later life. Br J Psychiatry $174: 307-311$

2. Greenstein SP, McGonigle D, Kellner CH (2017) Late life depression. In: Simon AB, New AS, Goodman WK, Mount sinai expert guides: Psychiatry. Chichester, West Sussex: John Wiley \& Sons, 312-321. 
3. Unützer J (2007) Clinical practice. Late-life depression. N Engl J Med 357: 2269-2276.

4. Hegeman JM, de Waal MW, Comijs HC, Kok RM, van der Mast RC (2015) Depression in later life: A more somatic presentation? J Affect Disord 170: 196-202.

5. Mitchell AJ, Rao S, Vaze A (2010) Do primary care physicians have particular difficulty identifying late-life depression? A meta-analysis stratified by age. Psychother Psychosom 79: 285-294.

6. Politis A, Economou M, Theleritis C (2018) The prevalence of mental disorders within the elderly population in Greece. In: Karl F, Ageing in the crisis: Experiences from Greece. ( $1^{\text {st }}$ edn), LIT Verlag, Germany.

7. European Health Interview Survey (EHIS) Questionnaire. Eurostat working group on public health statistics, 2007/2008

8. Fountoulakis $\mathrm{KN}$, Tsolaki $\mathrm{M}$, lacovides A, Yesavage J, O'Hara R, et al. (1999) The validation of the short form of Geriatric Depression Scale (GDS-15) in Greece. Aging (Milano) 11: 367-372.

9. Yesavage JA, Brink TL, Rose TL, Lum O, Huang V, et al. (1982) Development and validation of a geriatric depression screening scale: A preliminary report. J Psychiatr Res 17: 37-49.

10. Stylianopoulou C, Koulierakis G, Karagianni V, Babatsikou F, Koutis C (2010) Prevalence of depression among elderly on open care centers for older people. Vima-Asklipiou 9: 490-504.

11. Papadopoulos FC, Petridou E, Argyropoulou S, Kontaxakis V, Dessypris N, et al. (2005) Prevalence and correlates of depression in late life: A population based study from a rural Greek town. Int J Geriatr Psychiatry 20: 350-357.

12. Kanimozhi S, Mohan A Darbastwar (2017) Prevalence of depression in the elderly population of rural Puducherry: a community based cross sectional study. Int J Community Med Public Health 4: 4315-4320.
13. Babatsikou F, Konsolaki E, Notara V, Kouri M, Zyga S, et al. (2017) Depression in the Elderly: A descriptive study of urban and semi-urban Greek population. International Journal of Caring Sciences 3: 1286-1295.

14. Sözeri-Varma G (2014) Depression in the elderly: Clinical features and risk factors. Aging Dis 3: 465-471.

15. Tsang RS, Mather KA, Sachdev PS, Reppermund S (2017) Systematic review and meta-analysis of genetic studies of late-life depression. Neurosci Biobehav Rev 75: 129-139.

16. Djernes JK (2006) Prevalence and predictors of depression populations of elderly: A review. Acta Psychiatr Scand 113: 372-387.

17. Kaji T, Mishima K, Kitamura S, Enomoto M, Nagase $Y$, et al. (2010) Relationship between late life depression and life stressors: large-scale cross-sectional study of a representative sample of the Japanese general population. Psychiatry Clin Neurosci 64: 426-434.

18. Chang-Quan H, Zheng-Rong W, Yong-Hong L, Yi-Zhou X, Qing-Xiu L (2010) Education and risk for late life depression: A meta-analysis of published literature. Int J Psychiatry Med 40: 109-124.

19. Aziz R, Steffens DC (2013) What are the causes of late-life depression? Psychiatr Clin North Am 36: 497-516.

20. Argyropoulos K, Bartsokas C, Argyropoulou A, Gourzis P, Jelastopulu E (2015) Depressive symptoms in late life in urban and semi-urban areas of South-West Greece: An undetected disorder? Indian J Psychiatry 57: 295-300.

21. Allan CE, Valkanova V, Ebmeier KP (2014) Depression in older people is underdiagnosed. Practitioner 258: 19-22.

22. Volicer L, Frijters DHM, van der Steen JT (2011) Underdiagnosis and undertreatment of depression in nursing home residents. European Geriatric Medicine 6: 332-337.

23. Vanltallie TB (2005) Subsyndromal depression in the elderly: Underdiagnosed and undertreated. Metabolism 54: 39-44. 